\title{
Hospital value-based purchasing, market competition, and outpatient imaging efficiency
}

\author{
Mei Zhao ${ }^{1 \wedge}$, Hanadi Y. Hamadi ${ }^{1 \wedge}$, D. Rob Haley ${ }^{1}$, Kelly Pray ${ }^{2}$, Paul A. Heyliger-Fonseca ${ }^{3}$, \\ Aaron Spaulding ${ }^{4} \wedge$
}

${ }^{1}$ Department of Health Administration, Brooks College of Health, University of North Florida, Jacksonville, FL, USA; ${ }^{2}$ Management Engineering and Internal Consulting, Mayo Clinic in Rochester, Rochester, MN, USA; ${ }^{3}$ Defense Health Agency Supporting Navy, San Antonio, TX, USA; ${ }^{4}$ Department of Health Sciences Research, Division of Health Care Policy and Research, Mayo Clinic Robert D. and Patricia E. Kern Center for the Science of Health Care Delivery, Mayo Clinic, Jacksonville, FL, USA

Contributions: (I) Conception and design: M Zhao, DR Haley, A Spaulding; (II) Administrative support: K Pray, DR Haley, P Heyliger-Fonseca; (III) Provision of study materials or patients: M Zhao, HY Hamadi, A Spaulding, P Heyliger-Fonseca; (IV) Collection and assembly of data: HY Hamadi, M Zhao, A Spaulding, K Pray; (V) Data analysis and interpretation: M Zhao, HY Hamadi; (VI) Manuscript writing: All authors; (VII) Final approval of manuscript: All authors.

Correspondence to: Hanadi Y. Hamadi, PhD, MHA. Associate Professor, Department of Health Administration, Brooks College of Health, University of North Florida, 1 UNF Drive, Jacksonville, FL 32224-7699, USA. Email: h.hamadi@unf.edu.

Background: The Centers for Medicare \& Medicaid Services (CMS) collects data on hospital outpatient imaging efficiency (OIE) to reduce unnecessary exposure to contrast materials and prevent wasteful use of Medicare resources. In 2013, CMS implemented the Inpatient Hospital Value-Based Purchasing Program to improve quality and efficiency. There has been no systematic study that examines the association between hospital inpatient hospital value-based purchasing (HVBP) total performance, market competition, and OIE. This study fills the gap in the literature.

Methods: Using a longitudinal study design, data from the 2015-2018 American Hospital Association Annual Survey, the Medicare Hospital Compare, and the Area Health Resources Files (AHRF) database were utilized. Statistical analyses were conducted using fixed effects multivariate linear panel regression model for all hospitals $(n=4,093)$. The main outcome variables for this study were the six OIE variables measuring the efficient use of medical imaging tests, including magnetic resonance imaging (MRI) lumbar spine for low back pain, mammography follow-up rates, thorax computerized tomography use of contrast material, abdomen computerized tomography use of contrast material, cardiac imaging for preoperative risk assessment for non-cardiac low-risk surgery, and simultaneous use of brain computerized tomography and sinus computerized tomography. The main predictor variables were hospital inpatient total performance score (TPS) and hospital market concentration, defined by Herfindahl-Hirschman index (HHI).

Results: The multivariate panel data analysis indicated that hospitals with low TPSs also had a significantly lower rate of imaging services utilization for abdomen computerized tomography use of contrast material [coefficient $(\mathrm{b})=-0.58$; standard error $(\mathrm{SE})=-0.22$ ], indicating higher efficiency. also, hospitals in more competitive markets had a significantly higher rate of thorax computerized tomography use of contrast material $(b=0.59$; $\mathrm{SE}=-0.28)$, indicating lower efficiency of these services.

Conclusions: The findings from this study provide significant policy and practice implications. On the one hand, hospitals located in more competitive markets should consider strategies to improve their total performance to be better reimbursed by Medicare instead of offering more expensive outpatient imaging services. On the other hand, policymakers should monitor high performing hospitals since these hospitals also tend to provide more unnecessary outpatient imaging tests.

^ ORCID: Mei Zhao, 0000-0003-4218-463X; Hanadi Y. Hamadi, 0000-0001-9050-7267; D. Rob Haley, 0000-0001-8223-6073; Aaron Spaulding, 0000-0001-9727-6756. 
Keywords: Hospital value-based purchasing (HVBP); outpatient imaging efficiency (OIE); market competition

Received: 05 September 2020; Accepted: 22 January 2021; Published: 25 December 2021.

doi: $10.21037 /$ jhmhp-20-127

View this article at: http://dx.doi.org/10.21037/jhmhp-20-127

\section{Introduction}

In the early 2000s, diagnostic imaging technology increased rapidly with a parallel increase in outpatient medical imaging utilization. This increase in imaging utilization in the outpatient setting has provided value to the delivery of care but also has been associated with large growths in healthcare expenditures $(1,2)$. In addition, much of the increase in imaging has been deemed wasteful, and potentially harmful to patients $(3,4)$. This study seeks to investigate how the Hospital Outpatient Quality Reporting (OQR), and Hospital Value-Based Purchasing (HVBP) programs have affected hospital outpatient imaging efficiency (OIE).

Between 1996 and 2010, computed tomography (CT) examinations tripled with a $7.8 \%$ annual growth rate, and magnetic resonance imaging (MRI) quadrupled with a $10 \%$ annual growth (4). Key drivers for this increase include perceptions of positive clinical outcomes resulting from preventative imaging techniques, patient preferences, practice behaviors, and increased liability concerns leading physicians to utilize preemptive imaging steps for patient care (1). This increased usage of imaging technology eventually sparked exponential growth in expenditures for both patients and insurance companies $(2,3)$. In the latter part of the decade, the rate of outpatient medical imaging began to drop (5). Previously conducted studies attributed technological maturation, radiation awareness, market saturation, and increased policy implementation to the eventual slowing down of this exponential surge in medical imaging $(6,7)$. However, despite this reduction in the rate of growth, concerns surrounding the efficient use of imaging technologies abound (8-10).

The OQR program is a pay for quality data reporting program mandated through the Tax Relief and Health Care Act of 2006 (11). This program took effect in 2009 and was created to reduce unnecessary exposure to contrast materials and radiation, ensure adherence to evidence-based medicine and practice guidelines, and prevent wasteful use of Medicare resources. The hospital OQR consists of six outpatient medical imaging efficiency measures intended to capture the quality of outpatient imaging (12). Outpatient medical imaging efficiency indicates how often a hospital provides specific imaging tests for Medicare beneficiaries under circumstances where they may not be medically appropriate (13). Under the hospital OQR Program, hospitals must meet certain requirements or receive a two percentage point reduction in their annual payment update (APU) under the Outpatient Prospective Payment System (OPPS) (12).

In addition to providing hospitals with a financial incentive to report their quality of care measure data on outpatient services, the HVBP program was implemented in 2013. HVBP was launched as part of the Patient Protection and Affordable Care Act (ACA) of 2010 to increase population health outcomes and cost efficiency (14). The specific purpose of HVBP is to link hospital inpatient quality to payment. Currently, this program affects over 3,000 hospitals across the United States (15). Under this new payment system, hospitals are paid for inpatient acute care services based on the quality of care hospitals provide, not just the quantity of services.

The hospitals involved in HVBP must achieve certain performance standards to receive full reimbursement from Medicare. The HVBP imposes a financial penalty for hospitals that do not meet specific quality measures in the following domains: process, outcome, efficiency, and patient experience. Under HVBP, each of the previously mentioned domains is weighted and combined to calculate a total performance score (TPS), which is utilized to measure the hospital's value of care (15). In the fiscal year 2015, TPS was calculated based on the following weights for each domain: (I) clinical process of care (20\%), (II) patient experience of care $(30 \%)$, (III) outcome domain score $(30 \%)$, and (IV) efficiency domain score (20\%) (16).

Based on OQR and HVBP, it is clear that hospitals need to maintain a certain level of quality in both the inpatient and outpatient settings to ensure a higher level of payment from Medicare. The Centers for Medicare \& Medicaid Services (CMS) estimates that roughly half of participating hospitals will receive a net increase in payments, leaving half of the hospitals participating to experience a net decrease in payments (15). Previous studies have sought to address 
the shifting market in technological advancement and the policies implemented to curb unnecessary financial costs of diagnostic imaging, but these studies fail to examine the effect of TPSs and the current market condition (4,6,17-19). Therefore, it is important to examine the potential impact of HVBP incentives combined with market conditions on outpatient imaging services. These aspects of the care delivery environment are likely to heavily influence the care delivery process. We present the following article in accordance with the STROBE reporting checklist (available at http://dx.doi.org/10.21037/jhmhp-20-127).

\section{Conceptual framework}

Before 1983, hospitals were reimbursed based on costbased retrospective payment, which created a non-price competition among hospitals. This increased non-price competition among hospitals decreased hospital efficiency and increased hospital costs $(20,21)$. The prospective payment system (PPS), which started in 1983, exerted heavy cost reduction pressure on hospitals, and therefore, created price-based competition (22).

In 2013, the HVBP Program added another layer of financial incentives to hospitals through adjustments in payments to reward or penalize hospitals based on the quality of care that they provide to patients, rather than the quantity of care. The HVBP resulted in positive payment adjustments to over 1,800 participating hospitals (23). The bonus and penalty structure of this arrangement should promote additional efficiencies in the market as hospitals attempt to retain or gain payments from CMS. However, these arrangements are not likely to increase competition between hospitals as the incentive structure is not based on comparisons between hospitals but only an internal measurement of each hospital that falls within the program. Market competition, therefore, should not necessarily be affected by HVBP or the hospital OQR programs. However, market competition does influence which services are provided, as well as the cost of care (24). Therefore, when hospitals are located in a more competitive market, they may use more than necessary outpatient imaging services to satisfy their patients' requests or to protect against lawsuits $(25,26)$.

Hypothesis 1: hospitals that are located in more competitive markets will have lower OIE.

Hospital inpatient quality of care is likely to influence outpatient efficiency. Although there have been conflicting findings, the positive effect of quality on efficiency has been increasingly observed (27). In a systematic review of the association between quality and cost, $34 \%$ of studies report that higher costs are associated with higher quality, and 30\% of the studies indicated that lower costs were associated with higher quality (27). Based on the literature, when resources are constrained, there seems to be an inevitable trade-off between quality and efficiency in the healthcare industry. For example, Morey and colleagues (28) found that a $1 \%$ increase in the quality of care was estimated to increase hospital cost by an average of $1.34 \%$. In addition, Schreyögg and Stargardt (29) found that increased costs for acute myocardial infarction cases were associated with better outcomes. However, subsequent findings indicate the association may not be as strong as initially believed (30).

Furthermore, how a hospital organizes and manages its inpatient services should be reflected in how it manages and organizes its outpatient services. As such, intentional adherence to policies and procedures which influence care practices should permeate the organization and should be evidenced by performance measures. The ACA promotes changes that can improve quality and efficiency through the implementation of HVBP and the TPS. Hospitals that perform well in TPS domains, and the overall TPS are likely directly focusing on these measures in an attempt to meet the criteria. Similarly, outpatient imaging performance measured by hospital OQR promotes best practices for outpatient imaging. Likely, the same management and practice focus that allows hospitals to score highly in HVBP measures are also utilized in the outpatient setting, allowing for better performance on OQR measures.

Hypothesis 2: hospitals that have higher inpatient quality of care will have higher outpatient medical imaging efficiency.

\section{Methods}

\section{Data sources, variables, and measures}

Our analytic sample comprises 732 nonfederal acute-care U.S. hospitals spanning 2015-2018 with 2,912 unique hospitals and a total of 4,093 observations. Data were obtained from the Hospital Compare database-OIE and TPS, the Area Health Resources Files (AHRF) database, and the American Hospital Association Annual Survey (AHA) database (31). The OIE database provides OIE information, such as the use of MRI, CT scans, and mammography (32). The TPS database provides the hospital TPSs under the HVBP program. The AHRF database provides the 
market variables such as market competition, aging population, and per capita income (33). Finally, the AHA annual survey offers hospital information such as bed size, ownership, payer mix, location, and others (34). We developed a nationwide panel data sample of nonfederal (U.S.) acute-care hospitals by merging hospital-level data from these three sources using the Medicare provider number. Hospitals with missing data were removed from the sample.

The dependent variables for this study come from the hospital OIE database. Six OIE variables were chosen by CMS (13) to measure the efficient use of medical imaging tests. These six measures are MRI lumbar spine for low back pain, mammography follow-up rates, thorax CT use of contrast material, abdomen CT use of contrast material, cardiac imaging for preoperative risk assessment for noncardiac low-risk surgery, and simultaneous use of brain CT and sinus CT. With each measure, the higher the score the lower the efficiency.

The key independent variables for this study include hospital inpatient TPS and market concentration, defined by Herfindahl-Hirschman index (HHI). The TPS is a combined single measure that determines the adjustment to reimbursement during one fiscal year under Medicare's HVBP program. TPS is derived from four domains in FY $2015-20 \%$ of clinical process of care, $30 \%$ of patient experience of care, $30 \%$ of outcome, and $20 \%$ of efficiency domains. Starting in FY 2018, the percentage for each domain changed to $25 \%$. The TPS is a continuous variable. To measure the threshold effect of the TPS on OIE, we separate this measure into three groups: low (bottom quartile of the TPS), high (top quartile of the TPS), and average (middle $50 \%$ of TPS).

The hospital HHI is the standard measure used in economic analyses of market competition $(35,36)$. The $\mathrm{HHI}$ is constructed by dividing the number of inpatient days for each facility by the total number of inpatient days within the county to obtain each hospital's share. The share of each facility then is squared, and the shares of all hospitals are summed to create an index. Market shares for hospitals in a county that belong to the same hospital system are combined and treated as the same organization because they do not compete. The HHI takes into account the relative size distribution of the hospitals in a market. It approaches zero when a market is occupied by a large number of hospitals of relatively equal size and hence more competitive. It reaches its maximum of one when a market is controlled by a single hospital and hence is less competitive. The HHI increases both as the number of hospitals in the market decreases, and as the disparity in size between those hospitals increases. Data from the American Hospital Association annual survey were used to calculate HHI. Because the market in this study was highly concentrated, we separated the market into two groups: the lowest quartile of the HHI and the reference group, which includes the second, third, and fourth quartiles.

Several other market variables were also included in the analysis. The percentage of population aged 65 or older, per capita income, and total hospital beds per 1,000 population may affect demand and supply for a hospital's services and thus are included in the model (36-38).

Hospital characteristic variables are also included to control for confounding factors. Hospital bed size, defined as the number of staffed hospital beds, may influence hospital medical imaging utilization and the OIE (39). Because hospital bed size ranges from very few beds to more than 2,000, we separated them into three categories: small (fewer than 100 beds), medium [100-399], and large (400 beds and more). Ownership status, defined as for-profit, not-for-profit, and public, may reflect different objectives, service provision, and ultimate quality and efficiency (40). Furthermore, variation in hospital payer mix may reflect differences in patient service needs and thus affect the utilization and efficiency of care (41). Hence, Medicaid and Medicare percentages of inpatient days are included in the model to control for this confounding factor. A Hospital system refers to either a multihospital or a diversified single hospital system, which may impact productive efficiency (42). Hospital located in rural counties, as opposed to urban ones, may not be exposed to powerful constituents who expect that these hospitals provide high efficiency of care (43). Finally, hospitals' case mix index, measured by the Medicare case mix index, may have the capabilities and experiences to ensure that their patients receive efficient care (44). The study was conducted in accordance with the Declaration of Helsinki (as revised in 2013). The Institutional Review Board (IRB) categorized the research as exempt since the study analyzed secondary data that is publicly available and informed consent was waived.

\section{Statistical analysis}

Both descriptive statistics and panel analyses are conducted for the study. Our data was a balanced short and wide panel, allowing us to examine a large number of hospitals over a shorter period. The statistical analysis for each of the six 
Table 1 Description of OIE for 1,080 U.S. acute-care hospitals (all hospitals; 2015-2018; n=4,083 hospital-years)*

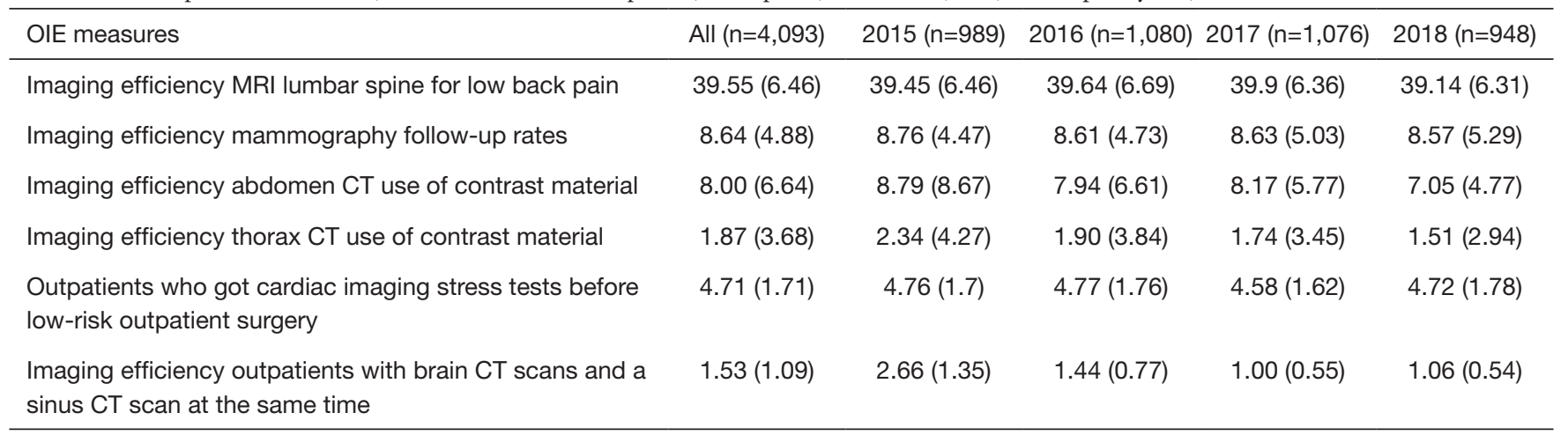

*, for all continuous variables mean (SD) is reported. OIE, outpatient imaging efficiency; MRI, magnetic resonance imaging; CT, computed tomography; SD, standard deviation.

OIE variables was conducted by estimating linear panel regression models with both hospital-specific individual and year specific time fixed effects. As Wooldridge (45), we conducted the standard Hausman test and its alternative robust formulation, which resulted in the rejection of the random effects model—an alternative approach to account for individual heterogeneity. A fixed-effects (within) model examined the relationship between hospital TPS, HHI, and six OIEs, controlling for other market characteristics and hospital characteristics such as size, ownership, payer mix, hospital system, rural location, and case mix index.

In all regression models, we used year dummies to account for unobserved period-specific fixed effects, and time-variant hospital and market characteristics to account for hospital and environment changes over time. We also conducted a robustness check by analyzing panel data of only large hospitals (with at least 400 beds) that are most likely to have advanced OIE systems. All analyses were performed in Stata 14 SE (Stata, RRID: SCR_012763).

\section{Results}

Table 1 highlights the descriptive characteristics of all the outcome variables in this study. The six OIE measures serve as the dependent variables. For the facilities eligible to report MRI lumbar spine for low back pain for 2015-2018, the mean performance rate was $39.55 \%$. Similarly, the rate for imaging efficiency mammography follow-up was 8.64\%, $8.00 \%$ for imaging efficiency abdomen CT use of contrast material, $1.87 \%$ for imaging efficiency thorax CT use of contrast material, $4.71 \%$ for outpatients who got cardiac imaging stress tests before low-risk outpatient surgery, and
$1.53 \%$ for outpatients with brain CT scans who got a sinus CT scan at the same time. For imaging efficiency, MRI lumbar spine for low back pain, mammography followup rates, abdomen CT use of contrast material, and thorax CT use of contrast material, 2018 had the lowest mean performance rate. For outpatients who got cardiac imaging stress tests before low-risk outpatient surgery and imaging efficiency outpatients with brain CT scans and a sinus CT scan at the same time, the lowest mean performance rate was in 2017 and the highest being in 2016.

Table 2 highlights the descriptive characteristics of all the variables in this study. Hospital TPS is separated into three groups (low, average, and high) to measure the threshold effect. For all years sampled, the mean percentage of hospitals falling in the low $25 \%$ of TPS category was $32.79 \%, 28.68 \%$ of hospitals fell into the average $50 \%$ of TPS category, and $38.53 \%$ of hospitals fell into the high top $25 \%$ of TPS category. In 2018, $40.51 \%$ of hospitals were among those in the top $25 \%$ of TPS, the highest percentage than any other year. Consequently, in 2018, $30.59 \%$ of hospitals were among the low $25 \%$ of TPS, the lowest percentage than any other year. Another key independent variable is hospital market competition, measured by the HHI. The mean HHI of hospitals for all years sampled was 0.47 , indicating an overall competitive market. Furthermore, $21.64 \%$ of hospitals were among the high top $25 \%$ of HHI in 2015, the highest than any other year; conversely, in 2015, 35.59\% of hospitals were among the low bottom $25 \%$ of $\mathrm{HHI}$, the lowest than any other year.

Other market variables showed that $15.31 \%$ of the population were 65 years of age or older, and the average 
Table 2 Description of organizational and market characteristics for 1,080 U.S. acute-care hospitals (all hospitals; 2015-2018; n=4,083 hospital-years)*

\begin{tabular}{|c|c|c|c|c|c|}
\hline Organizational and market characteristics & All $(n=4,093)$ & $2015(n=989)$ & $2016(n=1,080)$ & $2017(n=1,076)$ & $2018(n=948)$ \\
\hline Low (bottom $25 \%$ of TPS) & 32.79 & 34.98 & 32.96 & 32.53 & 30.59 \\
\hline Average (middle 50\%) & 28.68 & 24.67 & 29.07 & 31.78 & 28.90 \\
\hline High (top $25 \%$ of TPS) & 38.53 & 40.34 & 37.96 & 35.69 & 40.51 \\
\hline \multicolumn{6}{|l|}{$\mathrm{HHI}, \%$} \\
\hline Low (bottom $25 \%$ of $\mathrm{HHI})$ & 37.50 & 35.59 & 38.06 & 37.55 & 38.82 \\
\hline Average (middle $50 \%$ of $\mathrm{HHI}$ ) & 42.51 & 42.77 & 41.39 & 42.57 & 43.46 \\
\hline High (top $25 \%$ of $\mathrm{HHI}$ ) & 19.99 & 21.64 & 20.56 & 19.89 & 17.72 \\
\hline Hospital beds/1,000 population, mean (SD) & $2.48(2.92)$ & $2.65(4.59)$ & $2.5(2.28)$ & $2.42(2.02)$ & $2.37(2.06)$ \\
\hline \multicolumn{6}{|l|}{ Hospital characteristics } \\
\hline \multicolumn{6}{|l|}{ Ownership, \% } \\
\hline Government (non-federal) & 14.39 & 14.36 & 14.81 & 14.03 & 14.35 \\
\hline For-profit & 9.92 & 10.11 & 10.09 & 9.76 & 9.70 \\
\hline Not-for-profit & 75.69 & 75.53 & 75.09 & 76.21 & 75.95 \\
\hline \multicolumn{6}{|l|}{ Size, \% } \\
\hline Small & 15.00 & 12.64 & 15.00 & 16.36 & 15.93 \\
\hline \multicolumn{6}{|l|}{ Part of a system, \% } \\
\hline No & 25.85 & 26.29 & 27.87 & 25.00 & 24.05 \\
\hline Yes & 74.15 & 73.71 & 72.13 & 75.00 & 75.95 \\
\hline Hospital Medicare percentage, mean (SD) & $52.45(11.56)$ & $52.9(11.22)$ & $51.55(12.31)$ & $52.41(11.27)$ & $53.06(11.30)$ \\
\hline Hospital Medicaid percentage, mean (SD) & $19.95(9.82)$ & $19.66(9.56)$ & $19.55(10.20)$ & $20.09(9.68)$ & $20.52(9.77)$ \\
\hline Outpatient revenue percentage, mean (SD) & $56.66(12.19)$ & $55.13(11.97)$ & $56.29(12.25)$ & $57.28(12.12)$ & $57.98(12.28)$ \\
\hline Case mix index, mean (SD) & $1.64(0.25)$ & $1.61(0.24)$ & $1.63(0.25)$ & $1.63(0.25)$ & $1.68(0.26)$ \\
\hline
\end{tabular}

*, for all indicator variables proportion estimates are reported and for continuous variables mean (SD) is reported. TPS, total performance score; HHI, Herfindahl-Hirschman index; SD, standard deviation. 
per capita income was $\$ 30,240$ for the sampled hospitals. In addition, the mean hospital beds were 2.48 per 1,000 residents. Of the hospitals surveyed, $24.58 \%$ were large hospitals, $60.42 \%$ were medium-sized, and $15 \%$ were small. Of these, $9.92 \%$ of the hospitals were for-profit, and $75.69 \%$ of the hospitals were not-for-profit. Roughly $74.15 \%$ of the hospitals surveyed were part of a system. Additionally, 22.38\% of the hospitals surveyed were in a rural location. The entire compilation of hospitals surveyed had an average case mix index of 1.64. The patient population consisted of about 52\% Medicare and 19.95\% Medicaid beneficiaries. Finally, the hospitals surveyed had an average outpatient revenue percentage mean of 56.66 .

Table 3 displays the multivariate analysis performed on the imaging efficiency variables. Compared to average TPS performance hospitals, the hospitals with low TPS (in the lowest quartile performance) had a significantly lower rate [coefficient $(b)=-0.58$; standard error $(\mathrm{SE})=-0.22$ ] of imaging services utilization for abdomen $\mathrm{CT}$ use of contrast material, indicating higher efficiency for one out of the six measures; no other imaging efficiency measures were statistically significant for low and high TPS. This result is inconsistent with hypothesis 2, as it highlights that a lower quality scoring inpatient setting may be correlated with higher imaging efficiency in an outpatient setting.

Compared to hospitals located in average competitive markets, hospitals with low $\mathrm{HHI}$ (more competitive market) had a significantly higher rate $(b=0.59$; $\mathrm{SE}=-0.28)$ of thorax CT use of contrast material, indicating lower efficiency of these services; there was no significant effect of the HHI on the other five OIE for low HHI and six OIE for high HHI. Per capita income was the only other market condition to provide some statistically significant findings. Two of the six OIE: MRI lumbar spine for low back pain and abdomen CT use of contrast material were associated with less efficient use of these services. These findings are inconsistent with hypothesis 1 .

Several hospital characteristics were significantly associated with OIE. Compared to the government hospitals, for-profit and not-for-profit hospitals had significantly higher OIE (lower percentage or rate indicating increased efficiency), but only with brain CT scans $(b=0.59$; $S E=-0.14)$ and sinus $C T$ scans at the same time $(b=0.33 ; \mathrm{SE}=-0.10)$. Conversely, for-profit $(b=-1.00$; $\mathrm{SE}=-0.31)$, and not-for-profit $(\mathrm{b}=-0.61 ; \mathrm{SE}=-0.23)$ had significantly lower OIE for cardiac imaging stress tests before low-risk outpatient surgery. Furthermore, notfor-profit hospitals had significantly lower OIE, but with mammography follow-up rates $(b=-1.22 ; \mathrm{SE}=-0.40)$ and abdomen CT use of contrast material $(b=-1.41$; SE $=-0.61$ ), as compared to government hospitals. Medium sized hospitals, as compared to small hospitals, were positively ( $b=0.69 ; \mathrm{SE}=-0.34$ ) associated with thorax $\mathrm{CT}$ use of contrast material, signifying less efficiency in these hospitals. Compared to small hospitals, large hospitals were found to have no significant findings for any of the six OIE. Rurality was found to have no significant impact on any of the six OIE measures. Further, the use of medical imaging in response to hospital Medicare percentage shows a negative relationship, signifying the percentage of Medicare patients in a hospital is related to higher imaging efficiency for imaging services in cardiac imaging stress tests before low-risk outpatient surgery. However, the Medicaid payer mix was negative related to OIE measures: mammography follows up rates, cardiac imaging stress tests before low-risk outpatient surgery, and brain CT scans and a sinus CT scan at the same time-indicating higher efficiency. A higher case mix index resulted in an overall higher OIE, with a statistically significant negative association with thorax CT use of contrast material and with brain CT scans and a sinus CT scan at the same time. The impact of being part of a system was only negatively associated with brain CT scans and a sinus CT scan at the same time (higher efficiency). Additionally, the outpatient revenue percentage was not statistically significant among any of the 6 OIE. Finally, as compared to 2015, the years 2016, 2017, and 2018 were found to be more efficient in the use of the following three OIE: abdomen CT use of contrast material, thorax CT use of contrast material, and brain CT scans and sinus CT scans at the same time. Compared to 2015, the year 2016 was found to be more efficient with mammography follow-up rates.

\section{Discussion}

With the introduction of the ACA, the government implemented policies to generate better access to healthcare, reduce costs, and improve the quality of care. The HVBP Program rewards hospitals with incentive payments or penalties depending on the quality of care provided to Medicare patients. The HVBP payment approach was designed to optimize outcomes and reduce costs, so hospitals are motivated to change how they organize and deliver care to survive. However, contrary to the purpose of HVBP, this study found that hospitals with lower total performance were more efficient in outpatient 
Table 3 Estimation of incremental effects of OIE on inpatient quality, hospital characteristics and market characteristics at U.S. acute-care hospitals [all hospitals ( $\mathrm{n}=2,692)$; balanced panel; 2015-2018]

\begin{tabular}{|c|c|c|c|c|c|c|}
\hline $\begin{array}{l}\text { Organizational and market } \\
\text { characteristics }\end{array}$ & \multicolumn{6}{|c|}{ Coefficient (SE) } \\
\hline \multicolumn{7}{|l|}{ Hospital TPS (referent: average) } \\
\hline High (top $25 \%$ of TPS) & $-0.031(-0.35)$ & $-0.06(-0.17)$ & $-0.14(-0.25)$ & $0.04(-0.13)$ & $-0.10(-0.10)$ & $0.04(-0.04)$ \\
\hline \multicolumn{7}{|l|}{ Market condition } \\
\hline \multicolumn{7}{|l|}{ HHI (referent: average) } \\
\hline Per capita income $(1,000 \mathrm{~s})$ & $0.59^{*}(-0.23)$ & $0.12(-0.11)$ & $0.53^{\star \star}(-0.17)$ & $0.13(-0.09)$ & $-0.03(-0.06)$ & $0.04(-0.03)$ \\
\hline Hospital beds $/ 1,000$ population & $-0.18(-0.31)$ & $-0.19(-0.15)$ & $0.14(-0.22)$ & $0.15(-0.12)$ & $-0.03(-0.09)$ & $0.001(-0.0)$ \\
\hline \multicolumn{7}{|l|}{ Hospital characteristics } \\
\hline \multicolumn{7}{|c|}{ Ownership [referent: government (non-federal)] } \\
\hline For-profit & $2.08(-1.13)$ & $0.27(-0.53)$ & $0.33(-0.81)$ & $-0.72(-0.42)$ & $-1.00^{\star \star}(-0.31)$ & $0.60^{\star \star \star}(-0.14)$ \\
\hline Not-for-profit & $0.83(-0.85)$ & $-1.22^{\star \star}(-0.40)$ & $-1.41^{*}(-0.61)$ & $-0.62(-0.32)$ & $-0.61^{\star \star}(-0.23)$ & $0.33^{\star \star}(-0.10)$ \\
\hline \multicolumn{7}{|l|}{ Size (referent: small) } \\
\hline Hospital Medicaid percentage & $-0.02(-0.02)$ & $-0.03^{\star \star}(-0.01)$ & $0.02(-0.01)$ & $-0.002(-0.01)$ & $-0.01^{*}(-0.01)$ & $0.01^{\star \star \star}(-0.003)$ \\
\hline Case mix index & $0.90(-0.99)$ & $0.25(-0.47)$ & $1.07(-0.71)$ & $-1.02^{* *}(-0.37)$ & $0.05(-0.27)$ & $-0.24^{\star}(-0.12)$ \\
\hline \multicolumn{7}{|l|}{ Part of a system (referent: no) } \\
\hline Yes & $0.59(-0.461)$ & $-0.19(-0.22)$ & $-0.08(-0.33)$ & $-0.10(-0.17)$ & $-0.074(-0.13)$ & $-0.13^{*}(-0.06)$ \\
\hline Outpatient revenue percentage & $-0.002(-0.02)$ & $0.01(-0.01)$ & $0.02(-0.01)$ & $0.01(-0.01)$ & $-0.002(-0.005)$ & $-0.002(-0.002)$ \\
\hline \multicolumn{7}{|l|}{ Year (referent: 2015) } \\
\hline 2016 & $-0.15(-0.40)$ & $-0.38^{\star}(-0.19)$ & $-0.87^{\star \star}(-0.28)$ & $-0.74^{\star \star \star}(-0.15)$ & $-0.01(-0.11)$ & $-1.09^{\star \star \star}(-0.05)$ \\
\hline 2017 & $-0.27(-0.62)$ & $-0.41(-0.30)$ & $-1.25^{\star \star}(-0.45)$ & $-1.13^{\star \star \star}(-0.23)$ & $-0.15(-0.17)$ & $-1.54^{\star \star \star}(-0.08)$ \\
\hline 2018 & $-1.36(-0.89)$ & $-0.57(-0.42)$ & $-2.58^{\star \star \star}(-0.64)$ & $-1.44^{\star \star \star}(-0.33)$ & $0.003(-0.24)$ & $-1.46^{\star \star \star}(-0.11)$ \\
\hline
\end{tabular}

${ }^{*}, \mathrm{P}<0.05 ;{ }^{* *}, \mathrm{P}<0.01,{ }^{* \star}, \mathrm{P}<0.001$. Robust $\mathrm{SEs}$ are in parentheses. OIE, outpatient imaging efficiency; SE, standard error; TPS, total performance score; HHI, Herfindahl-Hirschman index. 
imaging services utilization, though this only showed in the imaging efficiency of abdomen CT use of contrast material. This is also contrary to other researchers (46) who found that VA medical centers with high performance were generally more efficient. However, the direct impact of quality on efficiency was mixed when hospital quality was measured with different indicators (47). Our study used the TPS, which combined hospital inpatient process (later changed to patient safety), patient experience, outcome, and inpatient efficiency to examine the relationship between hospital quality and outpatient efficiency. The study results suggest that TPS reflects only the inpatient performance, but not the assumption of outpatient efficiency. This may also reflect that to obtain a higher inpatient TPS, hospitals may have overused these expensive outpatient imaging tests. Diagnostic imaging such as MRI and CT scans are usually very expensive; therefore, any inefficient use of those services could be a waste of scarce health care resources. Medicare realized the inefficient use of resources in the hospital outpatient department (HOPD) due to the different payment rates for the same service across different sites of care in 2014 (48). Thus, Medicare recommended adjusting the rates for certain services when provided in HOPDs, so they more closely align with the rates paid in freestanding physician offices to reduce costs.

Our study results also indicate that greater market competition resulted in lower OIE, though this is only significant in one of the six measures. This is consistent with other researchers' findings that market competition may not reduce costs or lead to greater efficiency in hospitals $(49,50)$. Possible reasons may be related to the nature that competition in the healthcare sector is heavily influenced by governmental policies regarding reimbursement to providers, the extent of health insurance coverage, level of out-of-pocket payments, and flexibility of choosing a provider (51).

A notable finding from this study is the positive effect of time trends on hospital outpatient efficiency. Hospital outpatient efficiency has been significantly improved for most of these imaging services between 2015 and 2018 . This is contrary to the findings from "Trends in Hospital Performance on the Medicare National Outpatient Imaging Metrics", which studied the same group of hospitals from 2011 to 2016 (52). This difference may reflect that hospitals have significantly improved their efficiency after its initial time of implementation of the Medicare Hospital Outpatient Quality Reporting Program (HOQRP), which includes "imaging efficiency" metrics evaluating appropriate utilization of imaging examinations.

Finally, a variety of hospital characteristics had a significant impact on OIE. Compared to governmentowned hospitals, private not-for-profit hospitals had significantly higher medical imaging efficiency, while this effect was barely observed in the for-profit hospitals. This is contrary to the literature that for-profit hospitals were more efficient than their counterparts (53). Hospital size was observed to have a little effect on OIE. This may reflect the fact that hospital size changes from year to year were not that significant. Additionally, hospital payer mix such as Medicare and Medicaid showed some significant influence on OIEs; this is especially obvious for Medicaid patients. The higher the percentage change of Medicaid patients, the higher efficiency of the hospital OIE, which is consistent with previous studies (54). Medicare covers most of the imaging services to patients, and non-self-pay patients are more likely to request otherwise expensive imaging tests than those paying out of pocket. However, the effect was either marginal or significant in only one of the six measures. Finally, a greater case mix index resulted in greater efficiency, most likely because hospitals with more complex patients are less likely to request or endorse unnecessary imaging tests.

While this study addressed a very important issue related to the effect of market conditions and quality on outpatient medical imaging efficiency, it has its limitations. First, hospital competition can be measured in a variety of ways. The HHI calculated market competition where the markets were defined by geopolitical boundaries based on counties. However, there are three other ways to define the market: fixed radius, variable radius, and patient flow (55). Second, although panel data availability can be an advantage, the application of panel data econometric techniques has its disadvantages. For example, because this study focuses on the relations between year-to-year changes in hospital OIE and year-to-year changes in hospital characteristics and markets, the data's signal-to-noise ratio may decline significantly. Nevertheless, this study provides important insights into the hospital market, quality, and outpatient efficiency with the latest data available.

\section{Conclusions}

This study provides important insights into the relationship between market competition and hospital OIE. Policymakers need to understand that policies that encourage a more competitive marketplace may contribute 
to hospital inefficiencies. For example, hospitals may compete by providing patients with more services than needed to increase patient satisfaction. Typically, providing more diagnostic services indicates providing a higher quality of care in the absence of patient outcome data. Therefore, policymakers should develop policies that encourage greater transparency for TPS measures that require outpatient imaging services.

Our research also indicates that regulations that encourage greater quality and efficiency within the inpatient experience, such as the ACA, may not translate into greater quality and efficiency for outpatient services. Therefore, policymakers need to keep in mind that favorable inpatient hospital quality measures may not be a proxy for outpatient quality and efficiency. Because of our findings and similar findings presented by Narayan et al. (52) health service researchers need to rigorously evaluate the effectiveness and appropriateness of hospital quality measures and help guide policymakers.

Finally, the findings presented in this study offer important implications for hospital administrators. The U.S. healthcare system is expected to continue to evolve toward greater efficiency and value in both the inpatient and outpatient settings. Administrators should prepare for a healthcare environment with a much greater cost and quality transparency $(56,57)$. As a result, the competition will likely be based on healthcare quality, with quality defined as providing optimal outcomes at a reasonable cost instead of providing more services with substandard outcomes.

\section{Acknowledgments}

Each author would like to thank their respective institution. Funding: None.

\section{Footnote}

Reporting Checklist: The authors have completed the STROBE reporting checklist. Available at http://dx.doi. org/10.21037/jhmhp-20-127

Data Sharing Statement: Available at http://dx.doi. org/10.21037/jhmhp-20-127

Conflicts of Interest: All authors have completed the ICMJE uniform disclosure form (available at http://dx.doi. org/10.21037/jhmhp-20-127). The authors have no conflicts of interest to declare.

Ethical Statement: The authors are accountable for all aspects of the work in ensuring that questions related to the accuracy or integrity of any part of the work are appropriately investigated and resolved. The study was conducted in accordance with the Declaration of Helsinki (as revised in 2013). The Institutional Review Board (IRB) categorized the research as exempt since the study analyzed secondary data that is publicly available and informed consent was waived.

Open Access Statement: This is an Open Access article distributed in accordance with the Creative Commons Attribution-NonCommercial-NoDerivs 4.0 International License (CC BY-NC-ND 4.0), which permits the noncommercial replication and distribution of the article with the strict proviso that no changes or edits are made and the original work is properly cited (including links to both the formal publication through the relevant DOI and the license). See: https://creativecommons.org/licenses/by-nc-nd/4.0/.

\section{References}

1. Hendee WR, Becker GJ, Borgstede JP, et al. Addressing overutilization in medical imaging. Radiology 2010;257:240-5.

2. Iglehart JK. The new era of medical imaging — progress and pitfalls. N Engl J Med 2006;354:2822-8.

3. Emanuel EJ, Fuchs VR. The perfect storm of overutilization. JAMA 2008;299:2789-91.

4. Smith-Bindman R, Miglioretti DL, Johnson E, et al. Use of diagnostic imaging studies and associated radiation exposure for patients enrolled in large integrated health care systems, 1996-2010. JAMA 2012;307:2400-9.

5. Levin DC, Rao VM, Parker L, et al. Bending the curve: the recent marked slowdown in growth of noninvasive diagnostic imaging. AJR Am J Roentgenol 2011;196:W25-9.

6. Lang K, Huang H, Lee DW, et al. National trends in advanced outpatient diagnostic imaging utilization: an analysis of the medical expenditure panel survey, 20002009. BMC Med Imaging 2013;13:40.

7. Levin DC, Rao VM, Parker L. The recent downturn in utilization of CT: the start of a new trend? J Am Coll Radiol 2012;9:795-8.

8. Ganduglia CM, Zezza M, Smith JD, et al. Effect of public reporting on MR imaging use for low back pain. Radiology 
2015;276:175-83.

9. Litkowski PE, Smetana GW, Zeidel ML, et al. Curbing the urge to image. Am J Med 2016;129:1131-5.

10. Levin DC, Rao VM. Factors that will determine future utilization trends in diagnostic imaging. J Am Coll Radiol 2016;13:904-8.

11. Casey MM, Prasad S, Klingner J, et al. Are the CMS hospital outpatient quality measures relevant for rural hospitals? J Rural Health 2012;28:248-59.

12. Zafar HM, Mills AM, Khorasani R, et al. Clinical decision support for imaging in the era of the patient protection and affordable care act. J Am Coll Radiol 2012;9:907-18.e5.

13. Centers for Medicare and Medicaid Services. Hospital Outpatient Quality Reporting Program. 2016. Available online: https://www.cms.gov/Medicare/Quality-InitiativesPatient-Assessment-Instruments/HospitalQualityInits/Ho spitalOutpatientQualityReportingProgram.html

14. Blumenthal D, Jena AB. Hospital value-based purchasing. J Hosp Med 2013;8:271-7.

15. Centers for Medicare and Medicaid Services. Total Performance Score Information. 2016. Available online: https://www.medicare.gov/hospitalcompare/data/totalperformance-scores.html

16. Centers for Medicare and Medicaid Services. National Provider Call: Hospital Value Based Purchasing. 2015. Available online: https://www.cms.gov/outreach-andeducation/outreach/npc/downloads/hospvbp_fy15_npc_ final_03052013_508.pdf

17. Levin DC, Rao VM. Turf wars in radiology: updated evidence on the relationship between self-referral and the overutilization of imaging. J Am Coll Radiol 2008;5:806-10.

18. Hillman BJ, Goldsmith J. Imaging: the self-referral boom and the ongoing search for effective policies to contain it. Health Aff (Millwood) 2010;29:2231-6.

19. Schuur JD, Brown MD, Cheung DS, et al. Assessment of Medicare's imaging efficiency measure for emergency department patients with atraumatic headache. Ann Emerg Med 2012;60:280-90.e4.

20. Robinson JC, Luft HS. The impact of hospital market structure on patient volume, average length of stay, and the cost of care. J Health Econ 1985;4:333-56.

21. Ozcan YA. Efficiency of hospital service production in local markets: the balance sheet of US medical armament. Socioecon Plann Sci 1995;29:139-50.

22. Meltzer D, Chung J, Basu A. Does competition under Medicare Prospective Payment selectively reduce expenditures on high-cost patients? Rand J Econ 2002;33:447-68.

23. Centers for Medicare and Medicaid Services. Fiscal Year (FY) 2016 Results for the CMS Hospital Value-Based Purchasing Program. 2016. Available online: https:// www.cms.gov/Newsroom/MediaReleaseDatabase/Factsheets/2015-Fact-sheets-items/2015-10-26.html

24. Carey K, Burgess JF Jr, Young GJ. Hospital competition and financial performance: the effects of ambulatory surgery centers. Health Econ 2011;20:571-81.

25. Chung JW, Ju MH, Kinnier CV, et al. Evaluation of hospital factors associated with hospital postoperative venous thromboembolism imaging utilisation practices. BMJ Qual Saf 2014;23:947-56.

26. Deshpande SP, Deshpande SS. Factors impacting perceived threat of malpractice lawsuits by various medical specialists. Health Care Manag (Frederick) 2011;30:55-65.

27. Hussey PS, Wertheimer S, Mehrotra A. The association between health care quality and cost: a systematic review. Ann Intern Med 2013;158:27-34.

28. Morey RC, Fine DJ, Loree SW, et al. The trade-off between hosptial cost adn quality of care - an exploratory empirical-analysis. Med Care 1992;30:677-98.

29. Schreyögg J, Stargardt T. The trade-off between costs and outcomes: the case of acute myocardial infarction. Health Serv Res 2010;45:1585-601.

30. Cohen D, Manuel DG, Tugwell P, et al. Does higher spending improve survival outcomes for myocardial infarction? Examining the cost-outcomes relationship using time-varying covariates. Health Serv Res 2015;50:1589-605.

31. American Hospital Association. American Hospital Association (AHA) annual survey databaseTM. Chicago, IL, 2015-2018.

32. Rosenkrantz AB, Doshi A. Characterizing the performance of the nation's hospitals in the hospital outpatient quality reporting program's imaging efficiency measures. J Am Coll Radiol 2015;12:166-73.

33. Health UDo, Services H. Health Resources and Services Administration, Bureau of Health Workforce (2013-2014). Area Health Resources Files (AHRF), 2015.

34. Henke RM, Karaca Z, Moore B, et al. Impact of health system affiliation on hospital resource use intensity and quality of care. Health Serv Res 2018;53:63-86.

35. Robinson JC. Hospital market concentration, pricing, and profitability in orthopedic surgery and interventional cardiology. Am J Manag Care 2011;17:e241-8.

36. Fareed N, Bazzoli GJ, Farnsworth Mick SS, et al. The 
influence of institutional pressures on hospital electronic health record presence. Soc Sci Med 2015;133:28-35.

37. Bazzoli GJ, Fareed N, Waters TM. Hospital financial performance in the recent recession and implications for institutions that remain financially weak. Health Aff (Millwood) 2014;33:739-45.

38. Zhao M, Bazzoli GJ, Clement JP, et al. Hospital staffing decisions: does financial performance matter? Inquiry 2008;45:293-307.

39. Foster D, Zrull L. 100 top hospitals: hospital performance differences by size and teaching status. Truven Health Analytics, 2013.

40. Berney B, Needleman J, Kovner C. Factors influencing the use of registered nurse overtime in hospitals, 1995-2000. J Nurs Scholarsh 2005;37:165-72.

41. Czypionka T, Kraus M, Mayer S, et al. Efficiency, ownership, and financing of hospitals: the case of Austria. Health Care Manag Sci 2014;17:331-47.

42. Swofford M. Rural hospital system affiliations and their effects on hospital economic performance, 2004-2008. VCU Scholars Compass, 2011.

43. Younis MZ. A comparison study of urban and small rural hospitals financial and economic performance. Online J Rural Nurs Health Care 2012;3:38-48.

44. Fareed N, Mick S. To make or buy patient safety solutions: a resource dependence and transaction cost economics perspective. Health Care Manage Rev 2011;36:288-98.

45. Wooldridge JM. Econometric analysis of cross section and panel data. London: MIT Press, 2010.

46. Gao J, Moran E, Almenoff PL, et al. Variations in efficiency and the relationship to quality of care in the veterans health system. Health Aff (Millwood) 2011;30:655-63.

47. Gholami R, Higón DA, Emrouznejad A. Hospital performance: efficiency or quality? Can we have both with IT? Expert Syst Appl 2015;42:5390-400.

doi: 10.21037/jhmhp-20-127

Cite this article as: Zhao M, Hamadi HY, Haley DR, Pray K, Heyliger-Fonseca PA, Spaulding A. Hospital value-based purchasing, market competition, and outpatient imaging efficiency. J Hosp Manag Health Policy 202 1;5:33.
48. Medicare Payment Advisory Commission. Report to the Congress: Medicare Payment Policy. 2015. Available online: http://www.medpac.gov/docs/default-source/ reports/mar2015_entirereport_revised.pdf

49. Johansen M, Zhu L. Market competition, political constraint, and managerial practice in public, non-profit, and private American hospitals. J Public Adm Res Theory 2014;24:159-84.

50. Özgen Narc1 H, Ozcan YA, Şahin İ, et al. An examination of competition and efficiency for hospital industry in Turkey. Health Care Manag Sci 2015;18:407-18.

51. Morrisey MA. Competition in hospital and health insurance markets: a review and research agenda. Health Serv Res 2001;36:191-221.

52. Narayan AK, Rosenkrantz AB, Wang GX, et al. Trends in hospital performance on the medicare national outpatient imaging metrics: a 5-year longitudinal cohort analysis. J Am Coll Radiol 2019;16:1604-11.

53. Leleu H, Al-Amin M, Rosko $M$, et al. A robust analysis of hospital efficiency and factors affecting variability. Health Serv Manage Res 2018;31:33-42.

54. Anderson ME, Glasheen JJ, Anoff D, et al. Impact of state medicaid expansion status on length of stay and in-hospital mortality for general medicine patients at US academic medical centers. J Hosp Med 2016;11:847-52.

55. Agency for Healthcare Research and Quality. 2016 Hospital Market Structure Files. 2016. Available online: https://www.hcup-us.ahrq.gov/toolssoftware/hms/hms.jsp

56. Bratzler DW. Trends towards outcomes, accountable care, and value-based purchasing. In: Hassell LA, Talbert ML, Pine Wood JP. editors. Pathology practice management. Cham: Springer, 2016:17-21.

57. Revere FL, Ratanatawan A, Donderici EY, et al. A consumer-based evaluation of healthcare price and quality transparency. J Health Care Finance 2016;43:1-22. 